\title{
Characterization of Serine Protease Inhibitor from Solanum tuberosum Conjugated to Soluble Dextran and Particle Carriers
}

\author{
Erika Billinger,*i) Shusheng Zuo, and Gunnar Johansson \\ Department of Chemistry-BMC, Uppsala University, P.O. Box 576, SE-751 23 Uppsala, Sweden \\ Supporting Information
}

\begin{abstract}
A serine protease inhibitor was extracted from potato tubers. The inhibitor was conjugated to soluble, prefractionated dextran and titanium dioxide and zinc oxide nanoparticles. Conjugation to dextran was achieved by periodate oxidation of the dextran, followed by Schiff base coupling to inhibitor amino groups, and finally reduction, whereas the conjugation to the oxide particles was carried out by aminosilanization and carbonyldiimidazole activation. The inhibitory effect of the conjugated inhibitor was compared to that of free inhibitor in solution and with gelatin gel as a direct substrate. A certain degree of inhibitory activity was retained for both the dextran-conjugated and particle-conjugated inhibitors. In particular, the apparent $K_{\mathrm{i}}$ value of the dextran-conjugated inhibitor was found to be in the same range as that for free inhibitor. The dextran conjugate retained a higher activity than the free inhibitor after 1 month of storage at room temperature.
\end{abstract}

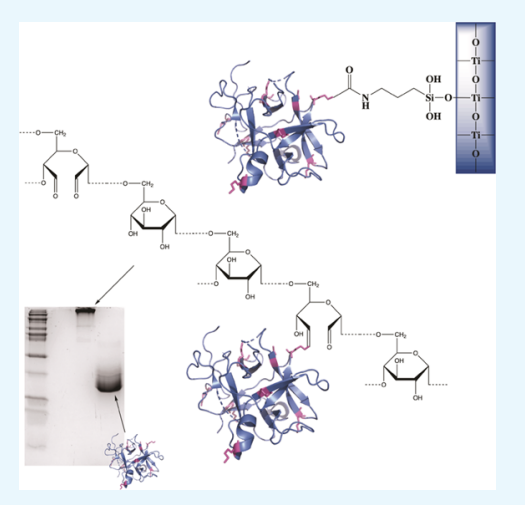

\section{INTRODUCTION}

Endogenous proteases, such as the serine proteases trypsin and chymotrypsin, are essential for the digestion in the host. However, these enzymes can also cause medical problems such as skin inflammation or acute pancreatitis. ${ }^{1,2}$ As a general protection, several endogenous protease inhibitors are also expressed, such as the pancreas trypsin inhibitor and $\alpha$-1antitrypsin. Protease inhibitors are also present in seeds and tubers in various plant families, including Solanaceae, potato family. As an example, protease inhibitors extracted from Solanum tuberosum, common potato, have inhibiting effects on digestive enzymes such as trypsin, chymotrypsin, and elastase. $^{3-6}$ Inhibitory effects on cell growth have also been observed. ${ }^{7,8}$ Protease inhibitors have already been successfully tested clinically both in vitro and in vivo.'

The wide range of serine protease inhibitors that are expressed in potato ( $S$. tuberosum) and mentioned above serve as a crucial defense mechanism against protein digestion by self, fungal, and bacterial proteases. ${ }^{10,11}$ Among these inhibitors, a Kunitz-type inhibitor (potato serine protease inhibitor, PSPI) is the most abundant ${ }^{11}$ and accounts for about $20 \%$ of the soluble proteins. ${ }^{12}$ The configuration of the reactive loop for PSPI is not fully known, but some authors suggest that it represents a two-headed reactive group type; it has also been shown that PSPI can not only bind two different proteases at the same time, i.e., trypsin and chymotrypsin, but also two trypsins due to its two independent binding loops. ${ }^{10,13,14}$ The inhibition effect of potato serine protease inhibitor on endogenous proteases has been proven as a remedy against severe dermatitis caused under certain conditions. ${ }^{15}$

A conjugation to selected carriers can increase the convenience of use in different applications, ${ }^{16-18}$ e.g., by inclusion in skin protection formulas. Furthermore, conjuga- tion can often have favorable effects on the resistance to high temperatures and harsh chemical environments and may improve the stability of the protein. This study describes the conjugation of PSPI to dextran and to solid carriers, i.e., zinc oxide and titanium dioxide particles, all of which are used in medical and hygiene applications. To the best of our knowledge, no immobilization protocol for PSPI has been reported so far. Dextran is biocompatible ${ }^{19}$ and has previously been documented as an excellent carrier for different proteins and is here chosen for this purpose. ${ }^{20,21,24,25}$ Among the different conjugation methods between dextran and proteins, ${ }^{24-31}$ the periodate oxidation method is effective, feasible, and thus well-established. ${ }^{20}$ Furthermore, it does not lead to a direct dextran-dextran cross-linking. In this study, prefractionated water-soluble dextran with $150-190 \mathrm{kDa}$ molar mass was used to conjugate PSPI by the periodate oxidation method, and the result of the conjugation was analyzed by a combination of light-scattering, chromatography, and concentration measurements. ${ }^{21}$ The conjugation to the oxide particles was carried out by aminosilanization followed by carbonyldiimidazole (CDI) activation. ${ }^{22,23}$

Our aims in the present work were to (1) establish conjugation protocols for the protease inhibitor from $S$. tuberosum onto soluble and particle carriers and (2) characterize the stability and kinetics parameters of the conjugated PSPI.

Received: August 31, 2019

Accepted: October 11, 2019

Published: October 25, 2019 


\section{RESULTS AND DISCUSSION}

Dextran Size Refractionation, Quantification, and Light-Scattering Analysis. The dextran concentration and mass distribution in the eluates of size exclusion chromatography are shown in Figure 1a, and the dextran concentration in
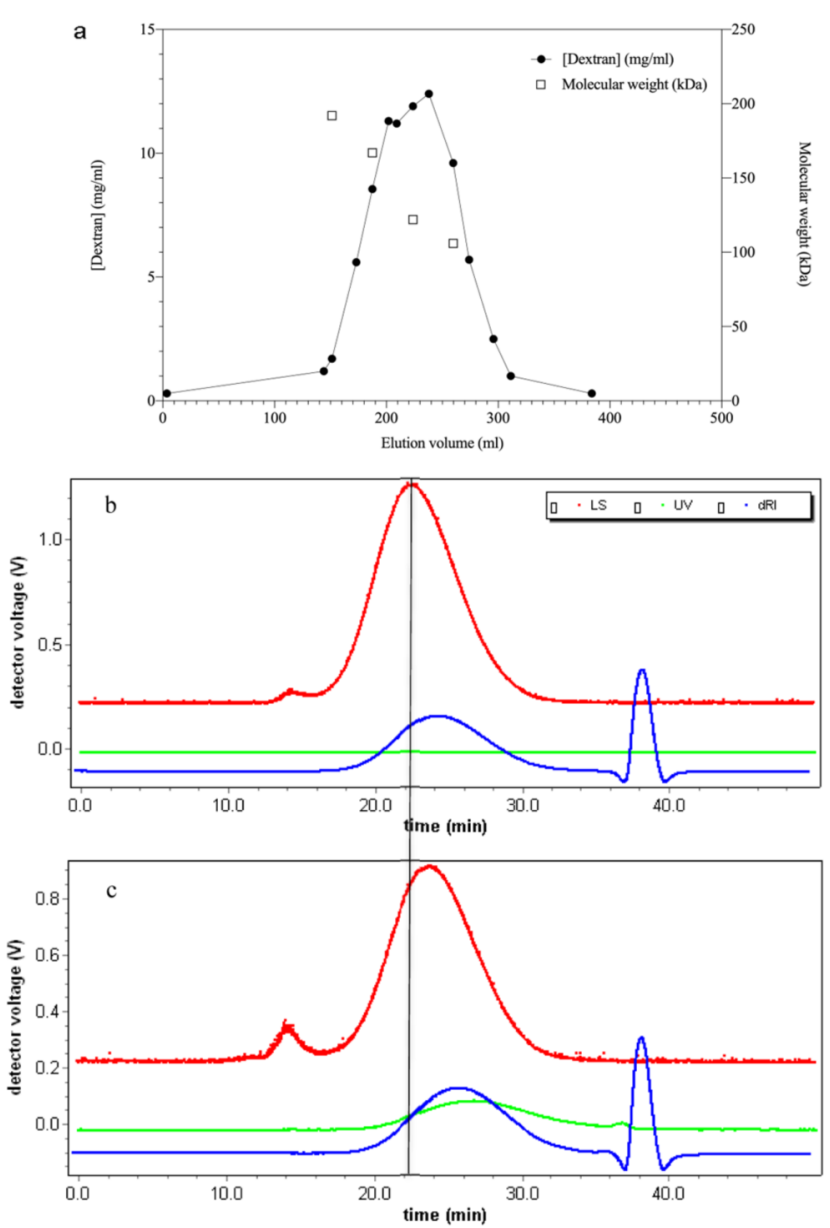

Figure 1. (a) Dextran concentration measured by the DNS assay ( and molecular weight determined by light scattering $(\square)$ as a function of elution volume $(\mathrm{mL})$. (b) Light-scattering chromatogram of dextran $10 \mathrm{mg} / \mathrm{mL}$ and (c) light-scattering chromatogram of oxidized dextran $10 \mathrm{mg} / \mathrm{mL}$. The shift to the right in elution position for the oxidized dextran is demonstrated by the vertical black line. Upper (red) line represents scattering intensity, flat (green) line represents absorbance at $280 \mathrm{~nm}$, and the lowest (blue) line represents differential refractive index.

the major fractions was between 6 and $12.8 \mathrm{mg} / \mathrm{mL}$. The sensitivity limit of the sugar measurement by the 3,5dinitrosalicylic acid (DNS) method is $0.3 \mathrm{mg} / \mathrm{mL}$ dextran based on a standard curve. The light-scattering analysis of unfractionated dextran T70 (Figure 1b) displays a major mass spread from 151 to $60 \mathrm{kDa}$. The fractionation by size exclusion chromatography resulted, as expected, in a narrower size range. Oxidized dextran displayed a generally later elution peak compared to the intact dextran (Figure 1c).

The analyzed peak of each sample is divided into front, peak, and back to highlight the distribution of the molecular weight of each sample in the peak. The value of each sample peak as a whole is also included. The oxidation of dextran resulted in a decrease in molecular weight from 68 to $17 \mathrm{kDa}$, indicating that a degradation has taken place (Table 1), assuming the
Table 1. Light-Scattering Analysis of Dextran and Its Derivatives (kDa)

\begin{tabular}{lcccc} 
& $\begin{array}{c}M_{\mathrm{w}} \\
\text { front }\end{array}$ & $\begin{array}{c}M_{\mathrm{w}} \\
\text { peak }\end{array}$ & $\begin{array}{c}M_{\mathrm{w}} \\
\text { back }\end{array}$ & $\begin{array}{c}M_{\mathrm{w}} \\
\text { whole }\end{array}$ \\
dextran, $10 \mathrm{mg} / \mathrm{mL}$ & 116 & 61 & 31 & 68 \\
oxidized dextran, $10 \mathrm{mg} / \mathrm{mL}$ & 32 & 11 & & 17 \\
alternative 1, conjugate $40 \mu \mathrm{M}$ & 658 & 182 & & 396 \\
\hline
\end{tabular}

same value for the specific refractive index increment $d n / d c$. An example of one conjugate (alt 1) is also shown in Table 1 to illustrate the larger molecular weight of the conjugate. The theoretical mass averages for the total sample contents were calculated using the well-known expressions below (eq 1).

$$
M_{\mathrm{w}}=\frac{\sum M_{\mathrm{i}}^{2} n_{\mathrm{i}}}{\sum M_{\mathrm{i}} n_{\mathrm{i}}}=\frac{\sum c_{\mathrm{i}} M_{\mathrm{i}}}{\sum c_{\mathrm{i}}}
$$

Conjugation of Oxidized Dextran and PSPI. The conjugation was carried out using five different alternatives following the same general principle. The alternatives differed in the ratio between oxidized dextran and PSPI, time of incubation, amount of reducing agent, and whether the alternatives were neutralized with $\mathrm{HCl}$. All data regarding the conjugation can be found in Table 2 . In the analysis of the conjugation according to alternative 1 , the size-exclusion chromatography showed two elution peaks (Figure 3a), one for conjugate and one for nonconjugated inhibitor, probably due to the considerably high PSPI/oxidized dextran molecule ratio (6.95) and the initial presence of $0.1 \mathrm{M} \mathrm{NaBH}_{3} \mathrm{CN}$. The sodium dodecyl sulfate-polyacrylamide gel electrophoresis (SDS-PAGE) analysis showed that this conjugate stayed close to the top of the separation gel, confirming a very large size (Figure 3a, lane 2) compared to that of the free PSPI (Figure 3a, lane 3). Light-scattering analysis (Figure $3 \mathrm{~b}$ and Table 1) revealed an average molecular weight of the same conjugate of approximately $400 \mathrm{kDa}$. It is obvious, both from scattering data and chromatogram itself, that the conjugation resulted in a considerable increase in molecule size and mass. This prominent increase in molecule size and mass can not be explained by the formation of isolated complexes between proteins and single dextran molecules but may reveal a degree of protein-mediated cross-linking. As can be seen in Figures 2,5 , and 6 , there are 10 lysine residues (marked in magenta in the structure) available for conjugation but thus also for crosslinking. The formation of the bond between oxidized dextran and PSPI is shown in detail in Figure 2.

In the conjugation alternative 2 , the molar ratio between PSPI and oxidized dextran was 1.67. The size-exclusion chromatography showed that only one peak, eluting generally somewhat later than the first peak observed from alternative 1, but no separated free PSPI peak was observed in the elution volume range expected for that (Figure 4). The SDS-PAGE analysis further confirmed this, since the peak pools of the alternative 2 conjugate showed again a major material spread from close to the top of the separation gel with a smear further into the gel, but all of it migrating slower than the free PSPI (Figure 4, lanes 1-4). These results indicated that all PSPI molecules were conjugated to the oxidized dextran. In conclusion, the procedure in alternative 2 resulted in complete conjugation, possibly due to the long overnight incubation. The conjugation alternatives 3-5 did also result in complete conjugation and a similar inhibitory efficiency (Table 2). 
Table 2. Conjugation Condition for Oxidized Dextran and PSPI with Each Conjugate Having the Corresponding Apparent $K_{\mathrm{i}}$ Value

\begin{tabular}{|c|c|c|c|c|c|c|c|}
\hline alternative & PSPI dextran mass ratio & incubation (h) & amount $\mathrm{NaBH}_{3} \mathrm{CN}$ & $\mathrm{NaBH}_{4}$ & $\mathrm{HCl}$ to neutralize & $K_{\mathrm{i}}(\mu \mathrm{M})$ & efficiency \\
\hline free PSPI & & & & & & $0.102 \pm 0.025$ & $1.00^{a}$ \\
\hline 1 & $0.59: 1$ & 2 & $100 \mathrm{mM}$, present throughout & \multicolumn{2}{|c|}{ no (stopped by Tris, pH 9.0) } & $0.277 \pm 0.032$ & 0.37 \\
\hline 2 & $0.18: 1$ & 22 & $1 \mathrm{mM}$, last $2 \mathrm{~h}$ & $100 \mathrm{mM}, 30 \mathrm{~min}$ & yes & $0.233 \pm 0.034$ & 0.44 \\
\hline 3 & $0.18: 1$ & 23 & no & $100 \mathrm{mM}, 30 \mathrm{~min}$ & yes & $0.191 \pm 0.025$ & 0.53 \\
\hline 4 & $0.09: 1$ & 23 & no & $100 \mathrm{mM}, 30 \mathrm{~min}$ & yes & $0.171 \pm 0.036$ & 0.60 \\
\hline 5 & $0.33: 1$ & 23 & no & $100 \mathrm{mM}, 30 \mathrm{~min}$ & yes & $0.252 \pm 0.026$ & 0.41 \\
\hline
\end{tabular}

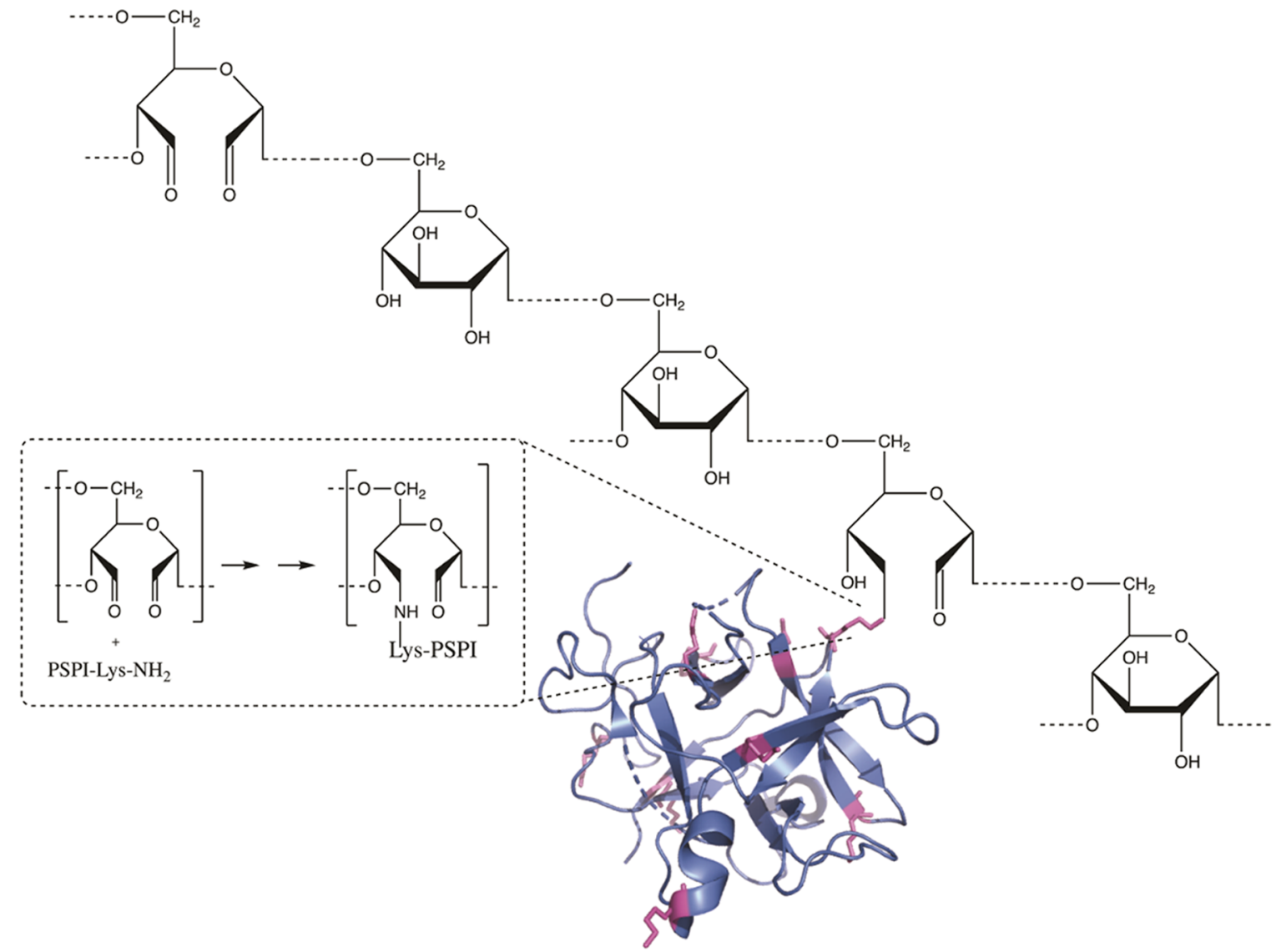

Figure 2. Schiff base formation followed by reduction between oxidized dextran and a primary amine of one lysine on PSPI gives the modeled dextran-PSPI conjugation (not correct scale). PDB ID: 3TC2.

However, the data reveal, as expected, a certain degree of protein-mediated cross-linking of the dextran carriers.

Inhibition Activity Analysis of Free and DextranConjugated PSPI. The double-reciprocal plots were analyzed by linear regression using GraphPad Prism $8 . K_{\mathrm{i}}$ was calculated according to eqs $1-3$, and the values are listed in Table 2 . Generally, the apparent $K_{\mathrm{i}}$ of the dextran-conjugated inhibitor molecules is approximately twice as high as that for the free inhibitor.

The apparent $K_{\mathrm{i}}$ values of the conjugates are obviously affected of which lysine(s) that serve in the conjugation and how close the conjugation is to the active site(s). It was earlier proposed $^{13,32}$ that this double-headed inhibitor could simultaneously bind two of the same or different proteases at the same time. The binding of two trypsins simultaneously to PSPI is definitely confirmed, whereas only one $\alpha$-chymotrypsin was bound. ${ }^{14}$ The active site(s) of PSPI have not been unequivocally identified due to the lack of complex structural data, but there are a number of theoretically proposed active sites (Figure 5) that are most commonly found in the protruding loops.

For monomeric Kunitz type serine protease inhibitor, it is most common that the section Ser71-Phe80 serves as an active site loop, with Phe75 being the P1 residue, so there is one proposed active site in PSPI located around Phe75 and, for the same reason, one around Lys95. It can be seen in Figures 5 and 6 that most of the possible conjugation sites most likely do not affect the inhibition of the protease(s). Since Lys95 also is a possible site for conjugation, the possible outcome that a number of the inhibitor molecules are conjugated by means of this residue will obviously affect the $K_{\mathrm{i}}$ value since that site is no longer available on all molecules.

The apparent $K_{\mathrm{i}}$ values are listed below in Table 2, and the apparent $K_{\mathrm{i}}$ values observed after 1 month of storage at different temperatures can be seen in Table 3. The apparent $K_{\mathrm{i}}$ values for dextran-PSPI conjugates lie within the same range 
a
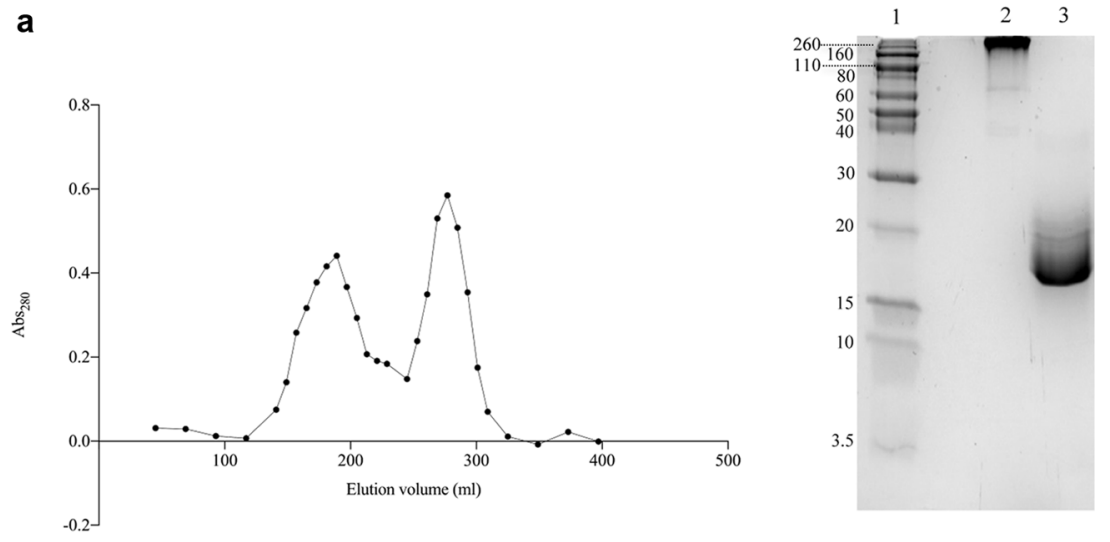

b

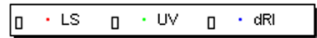

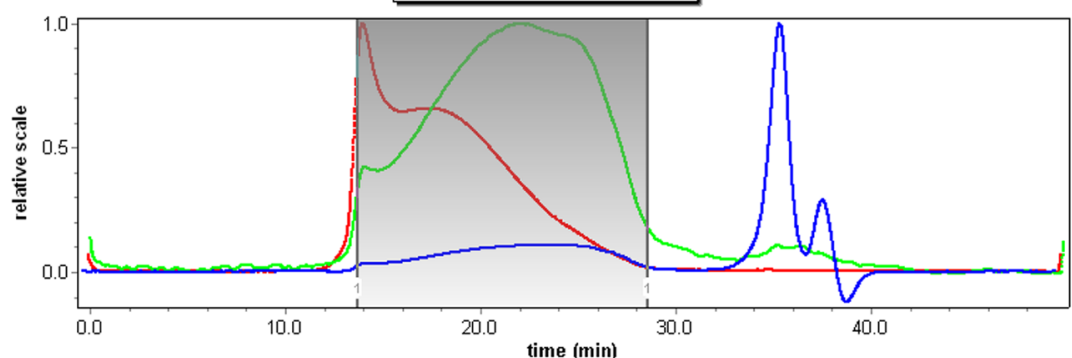

Figure 3. (a) Size-exclusion chromatogram of conjugation alternative 1 to the left and SDS-PAGE analysis of conjugate alternative 1 to the right. Lane 1: molecular standard ranging between 260 and $3.5 \mathrm{kD}$; lane 2: the 1st peak from size-exclusion chromatography representing conjugate; lane 3: the 2nd peak from size-exclusion chromatography representing free PSPI. (b) Light-scattering chromatogram of conjugate alternative 1. The marked area was the conjugate peak. Upper (red) line represents scattering intensity, flat (green) line represents absorbance at $280 \mathrm{~nm}$, and the lowest (blue) line represents differential refractive index.
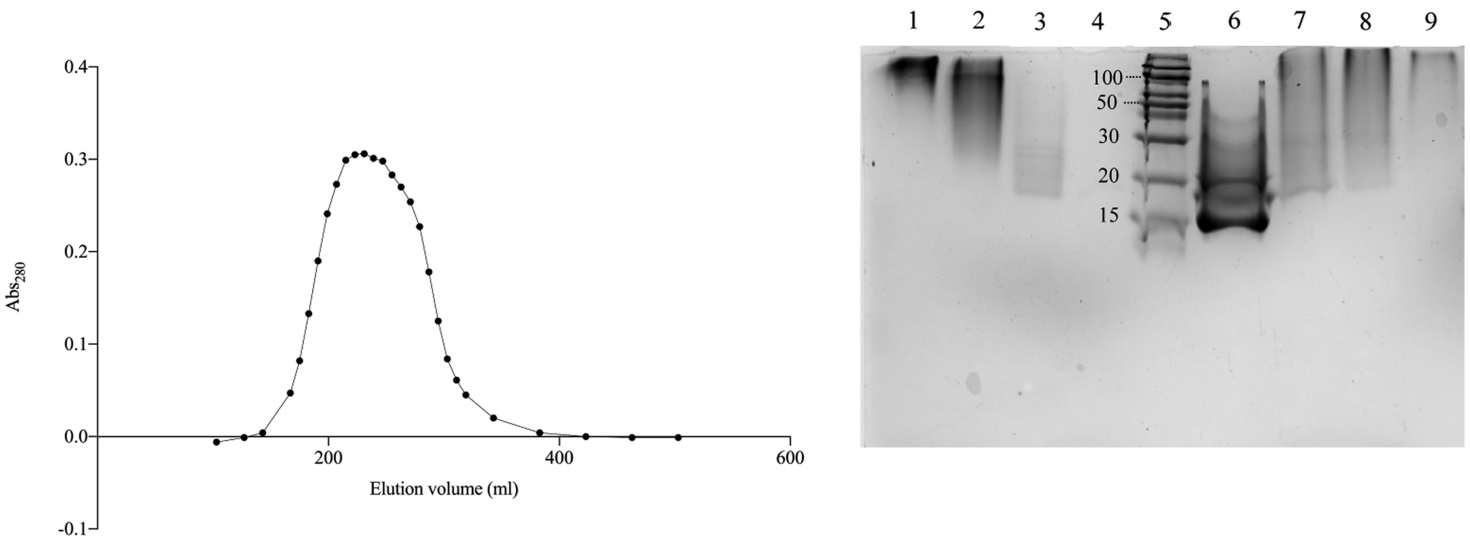

Figure 4. Size-exclusion chromatography on sephacryl S-300 for dextran-PSPI conjugation alternative 2 to the left. SDS-PAGE analysis for 2nd5 th conjugations to the right. Lanes 1-4: pools $2-5$ of the fractionated alternative 2, containing PSPI 6-14 $\mu$ g; lane 5: molecular standard (260$3.5 \mathrm{kD}$ ); lane 6: free PSPI, $16 \mu \mathrm{g}$; and lanes 7-9: dextran-PSPI conjugates from alternative 3, 4, and 5, respectively, containing 6-11 $\mu \mathrm{g}$ PSPI.

$\begin{array}{rrrrr}10 & 20 & 30 & 40 & \text { I } 50 \\ \text { LPSDATPVD } & \text { VTGKELDPRL } & \text { SYRIISTFWG } & \text { ALGGDVYLGK } & \text { SPNSDAPCAN } \\ 60 & 70 & \text { II } 80 & 90 & \text { III } 100 \\ \text { GVFRYNSDVG } & \text { PSGTPVRFIG } & \text { SSSHFGQGIF } & \text { EDELLNIQFA } & \text { ISTSKMCVSY } \\ 110 & 120 & 130 & 140 & 150 \\ \text { TIWKVGDYDA } & \text { SLGTMLLETG } & \text { GTIGQADSSW } & \text { FKIVKSSQFY } & \text { NLLYCPVTTS } \\ 160 & 170 & 180 & & \end{array}$

Figure 5. Sequence of PSPI where suggested active sites are marked in pink (I: Asn45-Asp50, II: Ser71-Phe80, III: around Lys95) and the ten possible conjugation sites are marked in magenta. Note that the proposed active site Lys 95 is also a possible conjugation site.

$(\mu \mathrm{M})$ and, compared to that of the free inhibitor, the $K_{\mathrm{i}}$ values increased by a factor of 1.7-2.6, which as mentioned above could be due to cross-linking and sterical hindrance. To evaluate the conjugates, we have chosen to use the parameter 

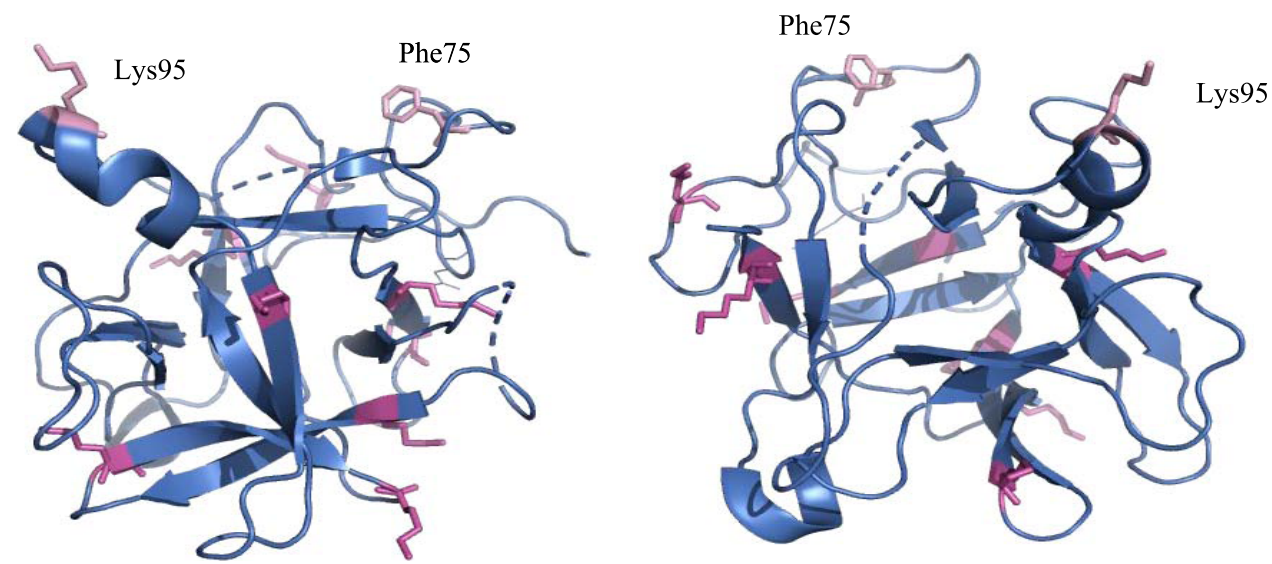

Figure 6. Model of PSPI where two of the possible reactive sites (Phe75 and Lys95) of this double-headed inhibitor are marked in pink. The possible conjugation sites (lysine) are marked in magenta. The model is also shown after a $180^{\circ}$ flip to better demonstrate possible conjugations sites. PDB ID: 3TC2.

Table 3. Apparent $K_{\mathrm{i}}$ Values Observed after 1 month of Storage of the Dextran-PSPI Conjugate Alternative 2 under Controlled Conditions Using Freshly Prepared Free Inhibitor as a Reference

\begin{tabular}{lcc}
\multicolumn{1}{c}{ alternative } & $K_{\mathrm{i}}(\mu \mathrm{M})$ & efficiency \\
fresh free inhibitor & $0.102 \pm 0.025$ & $1.00^{a}$ \\
conjugate stored at RT & $0.512 \pm 0.112$ & 0.20 \\
conjugate stored at $4{ }^{\circ} \mathrm{C}$ & $0.889 \pm 0.072$ & 0.12 \\
conjugate stored at $-20{ }^{\circ} \mathrm{C}$ & $0.599 \pm 0.057$ & 0.17 \\
free inhibitor stored at RT & $0.902 \pm 0.194$ & 0.11 \\
${ }^{a}$ Reference value. & & \\
\hline
\end{tabular}

efficiency as defined below. The efficiency is easily regarded as the fraction of inhibitor molecules that are functionally active, and the loss of efficiency can be ascribed to denaturation and/ or sterical inaccessibility. The efficiency is thus calculated from the apparent $K_{\mathrm{i}}$ value observed, $\frac{K_{\mathrm{i}, \text { free }}}{K_{\mathrm{i}, \text { app }}}=\frac{\left[\mathrm{I}_{\text {eff }}\right.}{\left[\mathrm{I}_{\mathrm{tot}}\right.}$. After the conjugation of PSPI to dextran, the inhibitor still remains $39-58 \%$ active in the different conjugation alternatives and remains $12-20 \%$ active after 1 month of storage. The SDSPAGE analysis (supplement) of the stored conjugates shows that they still remain intact and there are no traces of released PSPI, irrespective of the temperature of storage. A control experiment of free PSPI stored at RT for 1 month gave an apparent $K_{\mathrm{i}}$ value of $0.902 \mu \mathrm{M}$ (Supporting Information Figure S6), which shows an efficiency of 0.11 relative the freshly made free inhibitor with an apparent $K_{\mathrm{i}}$ of $0.102 \mu \mathrm{M}$ (Table 2). This shows that the conjugated PSPI are roughly twice as stable at room temperature than the free inhibitor.

Inhibition Activity Analysis of PSPI Conjugated to Activated Particles. The amount PSPI conjugated to activated particles was calculated to be $2.86 \mathrm{nmol} / \mathrm{mg}$ for $\mathrm{TiO}_{2}$ and $1.70 \mathrm{nmol} / \mathrm{mg}$ for $\mathrm{ZnO}$. During the conjugation, the conjugate of the particles and PSPI was exposed to $65{ }^{\circ} \mathrm{C}$ for 5 $\mathrm{h}$ during the buffer removal stage, and the conjugate still remains active with an apparent $K_{\mathrm{i}}$ value of $1.8 \mu \mathrm{M}$ for the $\mathrm{TiO}_{2}$-PSPI conjugate and $4.8 \mu \mathrm{M}$ for the $\mathrm{ZnO}$-PSPI conjugate (Table 4). A control experiment where the free PSPI was exposed to the same environment for the same time gave an apparent $K_{\mathrm{i}}$ value of $17 \mu \mathrm{M}$, which clearly indicates that the conjugates are more resistant to heat treatment. The efficiency (Table 4) of the conjugated inhibitor was thus
Table 4. Apparent $K_{\mathrm{i}}$ Values of Different Conjugates

\begin{tabular}{lcc}
\multicolumn{1}{c}{ state of PSPI } & $K_{\mathrm{i}}(\mu \mathrm{M})$ & efficiency \\
\hline free PSPI & $0.10 \pm 0.03$ & $1.00^{a}$ \\
$\mathrm{TiO}_{2}$-PSPI & $1.81 \pm 0.27$ & 0.06 \\
$\mathrm{ZnO}-\mathrm{PSPI}$ & $4.83 \pm 0.99$ & 0.02 \\
free PSPI after heat treatment & $17.3 \pm 1.13$ & 0.006 \\
${ }^{a}$ Reference value. & & \\
\hline
\end{tabular}

calculated to be 0.02 for $\mathrm{ZnO}$-PSPI and 0.06 for $\mathrm{TiO}_{2}$-PSPI, which, however, is better than that observed for free inhibitor subjected to the same heat treatment.

Inhibition Activity Analysis by the Gelatin Erosion Method. The gelatin erosion method was chosen as an additional method to evaluate the function of the conjugate since it mimics a process on a surface that needs a protective cover layer. The free PSPI and $-20{ }^{\circ} \mathrm{C}$ stored dextran-PSPI conjugate showed inhibition of both trypsin and chymotrypsin digestion actions on gelatin in a 24 -well plate. The ratio $\left(v_{\mathrm{i}} / v_{0}\right)$ between the area increase rate in the presence of inhibitor $\left(v_{\mathrm{i}}\right)$ and the area increase rate for the undisturbed enzyme $\left(v_{0}\right)$ was studied as a function of free PSPI and dextran-conjugated PSPI. The ratio $v_{0} / v_{\mathrm{i}}$ (Figures 7 and 8 ) was a linear function of inhibitor concentration, which is in accordance with competitive inhibition. The linear regression values extracted from the $v_{0} / v_{\mathrm{i}}$ graphs revealed that the gelatin erosion method displays a very similar behavior of the free and dextranconjugated PSPI, which can be seen in Table 5. The results from the gelatin erosion method show that there is no large difference between the conjugate and free PSPI. This indicates that the conjugation itself of PSPI does not affect the mode of action and that the conjugated inhibitor still can function similarly to the free PSPI in this type of experiment. The mechanism itself (competitive inhibition) is retained, since the $v_{0} / v_{\mathrm{i}}$ of the conjugate remains as a linear function of inhibitor concentration.

\section{CONCLUSIONS}

The SDS-PAGE analysis of the conjugates showed no traces of a band corresponding to the free inhibitor, proving that the inhibitory effects observed really depended on the conjugated inhibitor. The apparent $K_{\mathrm{i}}$ was influenced by the conjugation, most likely by the sterical hindrance, but increased at most by a factor of 2.6 for the fresh dextran conjugate. Conclusively, half 

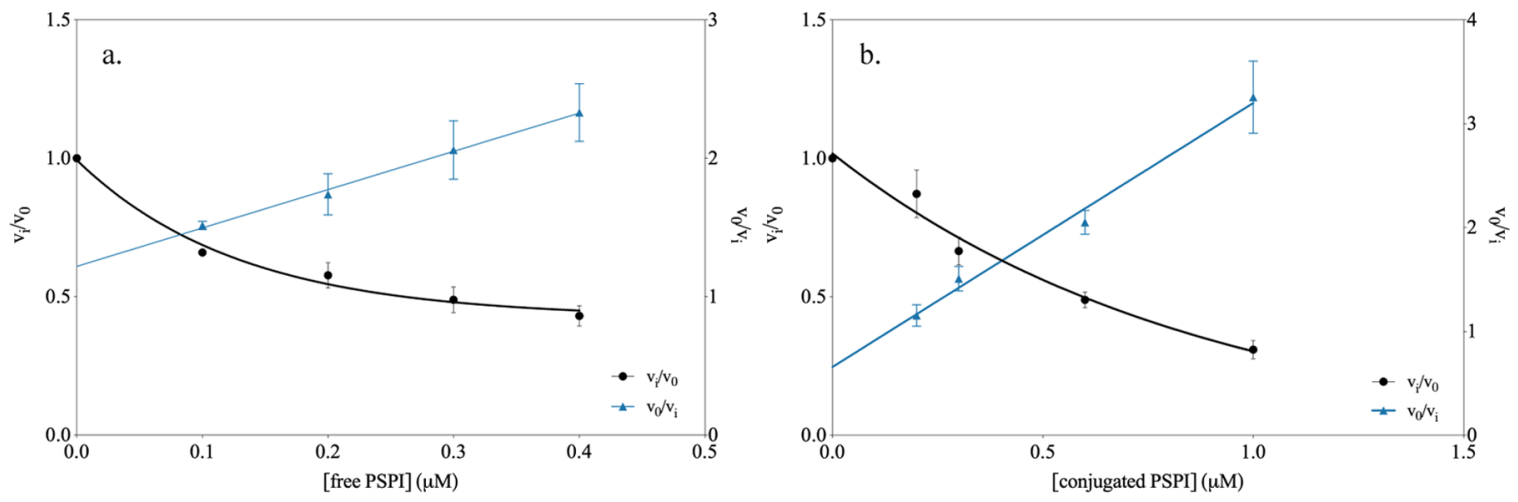

Figure 7. Inhibition of trypsin by free PSPI (a) and conjugated PSPI (b) studied by the gelatin erosion method.
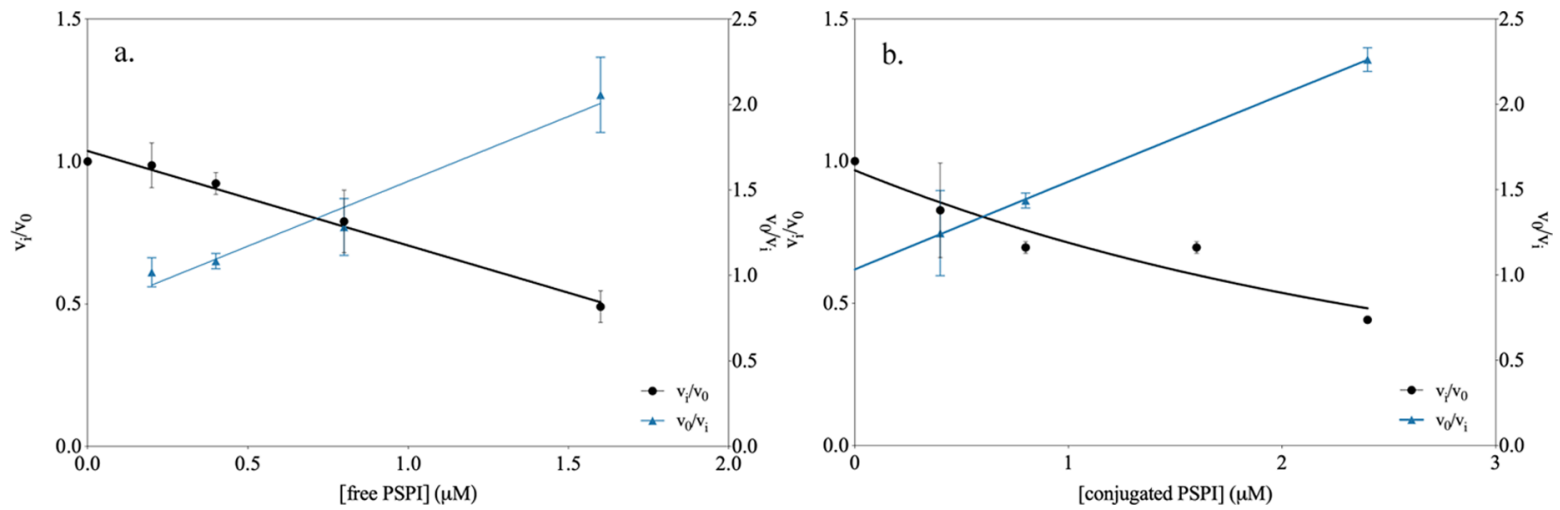

Figure 8. Inhibition of chymotrypsin by free (a) and conjugated PSPI (b) studied by the gelatin erosion method.

Table 5. Linear Regression Values Extracted from the $v_{0} / v_{\mathrm{i}}$ Graphs $^{a}$

\begin{tabular}{llc}
\hline enzyme & state of PSPI & slope from $v_{0} / v_{\mathrm{i}}$ \\
trypsin & free & $2.77 \pm 0.35$ \\
chymotrypsin & conjugated & $2.54 \pm 0.17$ \\
& free & $0.76 \pm 0.07$ \\
& conjugated & $0.51 \pm 0.05$
\end{tabular}

${ }^{a}$ Values Extracted from GraphPad Prism 8.

of the inhibitor molecules are, on the average, still accessible. There are 10 lysine residues, i.e., possible conjugation sites, on PSPI where one lysine also is postulated as a possible active site. The $K_{\mathrm{i}}$ value is affected by this random linkage between PSPI and activated dextran. Overall, the conjugation of PSPI leads to an increase in the apparent $K_{\mathrm{i}}$ value but still in an acceptable range. The conjugates showed an improved storage stability compared to the free inhibitor. Similarly, it was found that the conjugation of the inhibitor to the particles makes it more resistant to harsh heat treatment. The different conjugates will thus improve the applicability of the inhibitor both for medical/care purposes and use in biotechnology processes. The change in apparent $K_{\mathrm{i}}$ does, most certainly, reflect the limited availability of individual inhibitor molecules rather than a gradual change of the intrinsic properties of the molecules regarding both kinetics and binding equilibrium.

\section{MATERIALS AND METHODS}

Chemicals. Potatoes and commercial household gelatin powder (type A, from porcine source, Bloom number 220$240 \mathrm{~g}$ ), of the brand Törsleff's "favorit gelatin pulver-extra guld", were purchased from the local food shop. 3,5-
Dinitrosalicylic acid (DNS), K-Na tartrate, Dextran T70, sodium periodate $\left(\mathrm{NaIO}_{4}\right)$, sodium cyanoborohydride $\left(\mathrm{NaBH}_{3} \mathrm{CN}\right)$, sodium borohydride $\left(\mathrm{NaBH}_{4}\right)$, polyacrylamide, Coomassie Brilliant Blue R-250, N $\alpha$-benzoyl-L-arginine 4nitroanilide hydrochloride (BAPA), titanium dioxide, zinc oxide, aminopropyltriethoxysilane, carbonyldiimidazole, trypsin, and chymotrypsin were all purchased from Sigma-Aldrich. Protein molecular weight standard kit (260-3.5 kD) was purchased from Norvex. All other chemicals were of analytical grade.

Preparation of PSPI. The crude extraction and chromatographic separation were principally carried out according to the study by Pouvreau and Valueva. ${ }^{1,33}$ Potatoes were mixed with MQ water, followed by the precipitation of ammonium sulfate. After heat-shocking of the resuspension at $56{ }^{\circ} \mathrm{C}$ for $15 \mathrm{~min}$, the supernatant was reprecipitated by ammonium sulfate, and the resuspension was applied to desalting, cation exchange, and size-exclusion chromatography. The major fractions with high inhibition activity of PSPI in $0.1 \mathrm{M}$ phosphate-buffered saline (PBS), $\mathrm{pH} 7.4$, were collected and stored at $-20{ }^{\circ} \mathrm{C}$ after the absorbance measurement at $280 \mathrm{~nm}$. A value of $27305 \mathrm{M}^{-1}$ $\mathrm{cm}^{-1}$ for the molar extinction coefficients was used for the calculation of protein concentration.

Preparation of Dextran. Dextran Quantitation by the DNS Method. DNS reagent was prepared from 3,5dinitrosalicylic acid (DNS), K-Na tartrate, and $\mathrm{NaOH}^{34}$ Dextran T70 water solutions with concentrations ranging from 0.3 to $30 \mathrm{mg} / \mathrm{mL}$ were used as standards and MQ water as a control. Dextran samples $(0.1 \mathrm{~mL})$ were prehydrolyzed by boiling for $1 \mathrm{~h}$ with $1 \mathrm{~mL}$ of $1 \mathrm{M} \mathrm{HCl}$ and neutralized with 1 $\mathrm{mL}$ of $1 \mathrm{M} \mathrm{NaOH}$ after cooling. Then, $0.5 \mathrm{~mL}$ of the sample was mixed with $0.5 \mathrm{~mL}$ of DNS reagent. After boiling for $5 \mathrm{~min}$ 
and cooling, $4.5 \mathrm{~mL}$ of deionized water was added to the mixture and the absorbance at $540 \mathrm{~nm}$ was measured.

Dextran Prefractionation. A volume of $38 \mathrm{~mL}$ dextran T70 with concentrations of $30 \mathrm{mg} / \mathrm{mL}$ in MQ water was fractionated by size-exclusion chromatography on a sephacryl S-300 (2.6 × $60 \mathrm{~cm}^{2}$, GE Health Care, Uppsala, Sweden $)$ column at a flow rate of $0.2 \mathrm{~mL} / \mathrm{min}$ (Figure 1a). The dextran concentration in the fractions was determined by the DNS method. ${ }^{34}$ Two consecutive $7 \mathrm{~mL}$ fractions in the dextran peak were pooled and stored at $-20{ }^{\circ} \mathrm{C}$.

Dextran Mass Determination. Light-scattering analysis was performed by injecting $200 \mu \mathrm{L}$ of dextran or dextran derivatives solutions via a $200 \mu \mathrm{L}$ of loop into a Superdex 200 column $(10 \times 300 \mathrm{mM})$ connected sequentially with an interferometric refractometer (Wyatt technology, Optilab DSP), enhanced optical system (DAWN EOS, Wyatt technology), and UV flow spectrometer to determine the molar mass. A srii $(\mathrm{d} n / \mathrm{d} c)$ of $0.144 \mathrm{~mL} / \mathrm{g}$ was used for the molar mass calculation. $\mathrm{d} n / \mathrm{d} c$ is an easily measured change in $n$ with a change in $c$ (weight concentration, $\mathrm{g} / \mathrm{mL}$ ).

Conjugation of PSPI to Dextran. The prefractionated dextran pool was incubated with $50 \mathrm{mM} \mathrm{NaIO}_{4}$ for $1 \mathrm{~h}$ at room temperature, and the oxidized dextran was separated from the salts by gel chromatography on PD-10 columns using MQ water as an eluent. PSPI was then mixed with the oxidized dextran and incubated at selected times with or without the simultaneous presence of sodium cyanoborohydride $\left(\mathrm{NaBH}_{3} \mathrm{CN}\right)$ (Table 2).

Alternative 1: $10 \mathrm{~mL}$ of oxidized dextran $(5.3 \mathrm{mg} / \mathrm{mL})$ from the $190 \mathrm{kD}$ pool was mixed with $10 \mathrm{~mL}$ of potato protease inhibitor at $194 \mu \mathrm{M}$. The reaction was carried out in the presence of $0.1 \mathrm{M} \mathrm{NaBH}_{3} \mathrm{CN}$ at room temperature for $2 \mathrm{~h}$ and terminated by the addition of one-fifth volume of $1 \mathrm{M}$ Tris$\mathrm{HCl}, \mathrm{pH} 9.0$.

Alternative 2: $10 \mathrm{~mL}$ of oxidized dextran $(8.7 \mathrm{mg} / \mathrm{mL})$ from the $150 \mathrm{kD}$ pool was mixed with $5 \mathrm{~mL}$ of PSPI at $194 \mu \mathrm{M}$. The mixture was kept at room temperature overnight $(20 \mathrm{~h})$. $\mathrm{NaBH}_{3} \mathrm{CN}$ was then added at a final concentration of $1 \mathrm{mM}$ and the mixture was kept at room temperature for further $2 \mathrm{~h}$. The reaction was stopped by the addition of sodium borohydride $\left(\mathrm{NaBH}_{4}\right)$ at the final concentration of $0.1 \mathrm{M}$ for $30 \mathrm{~min}$, followed by neutralization to $\mathrm{pH} 7.0$ by the addition of $1 \mathrm{M} \mathrm{HCl}$. The resulting solution was filtered through a $0.2 \mu \mathrm{m}$ membrane and subjected to size-exclusion chromatography on Sephacryl S-300 at a flow rate of $0.5 \mathrm{~mL} / \mathrm{min}$. The peak fractions were collected in five pools (pool 1: 164-179 mL, pool 2: 180-203 $\mathrm{mL}$, pool 3: $204-243 \mathrm{~mL}$, pool 4: $244-283$ $\mathrm{mL}$, pool 5: $284-307 \mathrm{~mL}$ ). The absorbance at $280 \mathrm{~nm}$ of the fractions was measured, and those in the first peak, corresponding to the dextran-conjugated PSPI, were collected. The pools were stored at $-20^{\circ} \mathrm{C}$.

Alternatives 3-5: PSPI at $194 \mu \mathrm{M}$ was mixed with $8.7 \mathrm{mg} /$ $\mathrm{mL}$ oxidized dextran at $150 \mathrm{kD}$ with the volume ratios of $0.5: 1$, $0.25: 1$, and $0.1: 1$, respectively. The mixtures were incubated at room temperature for $23 \mathrm{~h}$, followed by the addition of $\mathrm{NaBH}_{4}$ and $\mathrm{HCl}$ as above. No $\mathrm{NaBH}_{3} \mathrm{CN}$ was used.

SDS-PAGE Analysis. PSPI and dextran conjugates were analyzed by SDS-PAGE on $13 \%$ polyacrylamide gel. The gel was stained with $0.5 \mathrm{mg} / \mathrm{mL}$ Coomassie Brilliant Blue R-250 in a solvent of $10 \%(\mathrm{v} / \mathrm{v})$ acetic acid, $40 \%(\mathrm{v} / \mathrm{v})$ methanol, and $50 \%(\mathrm{v} / \mathrm{v}) \mathrm{MQ}$ water and destained using the same solvent. Molecular standard $(260-3.5 \mathrm{kD})$ from Norvex was used.
Conjugation of PSPI to Inorganic Particles. Derivatization of Particles. All derivatization and immobilization steps were performed at room temperature in plastic falcon tubes. The inorganic particle carriers $\left(\mathrm{TiO}_{2}\right.$ and $\left.\mathrm{ZnO}\right)$ (0.5 grams) were first silanized using $100 \mathrm{mM}$ APTES in $10 \mathrm{~mL}$ of ACN while stirring for $24 \mathrm{~h}$. The silanized particles were then centrifuged, followed by the removal of $\mathrm{ACN}$, washing three times with $\mathrm{EtOH}$, one final time with acetone, and then drying at $65{ }^{\circ} \mathrm{C}$ overnight. The particles were activated using $120 \mathrm{mg}$ of CDI and $0.72 \mathrm{mmol}$ triethylamine in $5 \mathrm{~mL}$ of ACN while stirring for $3 \mathrm{~h}$. Then, the particles were centrifuged to remove $\mathrm{ACN}$, washed three times with $\mathrm{EtOH}$, one final time with acetone, and then dried at $65^{\circ} \mathrm{C}$ overnight.

Immobilization of PSPI. Immobilization of PSPI was carried out according to Table 6 . The particles were collected by

Table 6. Conjugation Conditions for Activated Particles and PSPI

\begin{tabular}{|c|c|c|c|c|}
\hline & $\begin{array}{c}\text { amount } \\
\text { activated } \\
\text { particles }(\mathrm{mg})\end{array}$ & $\begin{array}{c}\text { PSPI } \\
(\mathrm{nmol})\end{array}$ & $\begin{array}{l}\text { time of } \\
\text { reaction }\end{array}$ & buffer \\
\hline $\mathrm{TiO}_{2}$ & 100 & 482 & \multirow{2}{*}{$\begin{array}{l}24 \mathrm{~h} \text {, } \\
\text { while } \\
\text { stirring }\end{array}$} & $0.1 \mathrm{M} \mathrm{NH}_{4} \mathrm{HCO}_{3} \mathrm{pH} 7.52$ \\
\hline $\mathrm{ZnO}$ & 100 & 448 & & $0.1 \mathrm{M} \mathrm{NH}_{4} \mathrm{HCO}_{3} \mathrm{pH} 7.52$ \\
\hline
\end{tabular}

centrifugation, and the absorbance was measured at $280 \mathrm{~nm}$ for the supernatants. The remaining nonconjugated protein was determined. The immobilization was terminated by washing the particles with $0.1 \mathrm{M} \mathrm{NH} \mathrm{NCO}_{3} \mathrm{pH} 7.52$ followed by drying at $65{ }^{\circ} \mathrm{C}$ for $5 \mathrm{~h}$ and storage at $4{ }^{\circ} \mathrm{C}$ until further use.

Kinetics. Inhibition Activity Analysis of Free and Dextran-Conjugated PSPI. Kinetic parameters were obtained by measuring the initial velocities in the presence of varying concentrations of BAPA $(0-3 \mathrm{mM})$ mixed with free $(0.18-$ $0.34 \mu \mathrm{M})$ or dextran-conjugated PSPI $(0.18-0.34 \mu \mathrm{M})$. All reactions were performed in $0.1 \mathrm{M} \mathrm{NH}_{4} \mathrm{HCO}_{3}$ buffer, $\mathrm{pH} 7.52$, and $0-5 \%(\mathrm{v} / \mathrm{v})$ DMSO. The reaction was monitored at 410 $\mathrm{nm}$ in a UV-1601 UV-vis spectrophotometer (Shimadzu). The apparent $K_{\mathrm{i}}$ was extracted after fitting the data to linear regression in GraphPad Prism 8 according to the Lineweaver-Burk equation (eq 2) and its extended version (eq 3).

End Point Measurements for Inorganic Particle Conjugates. Kinetic parameters were obtained by incubating substrate, enzyme, and conjugate in a plastic Eppendorf tube with an end-over-end rotation. The concentrations of $\mathrm{TiO}_{2}$ PSPI varied between 2.65 and $5.71 \mu \mathrm{M}, \mathrm{ZnO}$-PSPI between 1.70 and $3.40 \mu \mathrm{M}$, and BAPA between 0 and $2 \mathrm{mM}$. All reactions were performed in $0.1 \mathrm{M} \mathrm{NH}_{4} \mathrm{HCO}_{3}$ buffer, $\mathrm{pH}$ 7.52, and $0-5 \%(\mathrm{v} / \mathrm{v})$ DMSO. One hundred fifty microliters of aliquots were withdrawn at 5 time points from each sample, and the reaction was stopped in $100 \mathrm{mM}$ acetic acid, $\mathrm{pH} 2.8$. Absorbance was measured at $410 \mathrm{~nm}$ in a UV-1601 UV-vis spectrophotometer (Shimadzu). The apparent kinetic parameter $K_{\mathrm{i}}$ was extracted after fitting the data to linear regression in GraphPad Prism 8.

$$
\frac{1}{v}=\frac{K_{\mathrm{m}}}{v_{\max }} \times \frac{1}{[\mathrm{~S}]}+\frac{1}{v_{\max }}
$$

And its extended version

$$
\frac{1}{v}=\frac{K_{\mathrm{m}}\left(1+[\mathrm{I}] / K_{\mathrm{i}}\right)}{v_{\max }} \times \frac{1}{[\mathrm{~S}]}+\frac{1}{v_{\max }}
$$


where $K_{\mathrm{m}, \text { app }}=K_{\mathrm{m}} \times\left(1+[\mathrm{I}] / K_{\mathrm{i}}\right)$

For alternatives $3-5, K_{\mathrm{i}}$ was calculated according to the following equation

$$
\frac{v_{0}}{v_{\mathrm{i}}}=\frac{K_{\mathrm{m}}\left(1+[\mathrm{I}] / K_{\mathrm{i}}\right)+[\mathrm{S}]}{K_{\mathrm{m}}+[\mathrm{S}]}
$$

Inhibition Activity Analysis by the Gelatin Erosion Method. The method was principally described earlier. ${ }^{35}$ Gelatin powder (type A, from porcine source, Bloom number 220-240 g) with a concentration of $0.04 \mathrm{~g} / \mathrm{mL}$ was dissolved in $0.1 \mathrm{M}$ PBS, $\mathrm{pH} 7.4$, at $38{ }^{\circ} \mathrm{C}$. After cooling to $30^{\circ} \mathrm{C}$, it was mixed with free or conjugated PSPI, 0.1 M PBS, and MQ water to get a gelatin concentration of $0.02 \mathrm{~g} / \mathrm{mL}$ and a series of PSPI concentration. A volume of $1 \mathrm{~mL}$ of mixture was added to a 24-well plate in quadruplicates for each PSPI concentration. After solidification at $4{ }^{\circ} \mathrm{C}$ for $1 \mathrm{~h}$, a volume of $20 \mu \mathrm{L}$ of $15 \mu \mathrm{M}$ trypsin or $20 \mu \mathrm{L}$ of $15 \mu \mathrm{M}$ chymotrypsin in $0.1 \mathrm{M}$ PBS, $\mathrm{pH} 7.4$, was pipetted on the center of the gelatin layer and the plates were covered with lids and incubated at 4 ${ }^{\circ} \mathrm{C}$ for $24 \mathrm{~h}$. The diameter of the erosion in the well was measured and the specific enlargement of the erosion area was calculated by subtracting the area that was observed when 20 $\mu \mathrm{L}$ of water was added instead of the enzyme solution.

The relative area growth rate $\left(v_{\mathrm{i}} / v_{0}\right)$ was analyzed as a function of the inhibitor concentration by GraphPad Prism 8 using the one-phase decay algorithm (eq 5).

$$
v_{\mathrm{i}} / v_{0}=(1-a) \mathrm{e}^{-K[\mathrm{I}]}+a
$$

where $K$ is the rate constant.

\section{ASSOCIATED CONTENT}

\section{S Supporting Information}

The Supporting Information is available free of charge on the ACS Publications website at DOI: 10.1021/acsomega.9b02815.

Standard curve of dextran by DNS method (S1); SDSPAGE analysis of conjugates made by alternatives 2-5 (S2); saturation curve and Line-Weaver Burk plot from kinetic measurements of dextran-PSPI conjugation by alternative 2 (S3); saturation curve and Line-Weaver Burk plot from kinetic measurements of stored dextranPSPI conjugation (S4); SDS-PAGE analysis of stored conjugates (S5); saturation curve from kinetic measurements of stability evaluation (S6) (PDF)

\section{AUTHOR INFORMATION}

\section{Corresponding Author}

*E-mail: erika.billinger@kemi.uu.se. Phone: +46 184714312. ORCID

Erika Billinger: 0000-0003-1710-9128

Notes

The authors declare no competing financial interest.

\section{ACKNOWLEDGMENTS}

We thank Xiaocheng Liu, Yuanbo Ren, Enrique Lopez Olvera, and Kajsa Eriksson for their contribution to the project during their examination work in the department. The project is supported by Bo Rydins foundation.

\section{ABBREVIATIONS}

PSPI,potato serine protease inhibitor

\section{REFERENCES}

(1) Nelson, D. L.; Cox, M. M. Principles of Biochemistry, 5th ed.; W.H. Freeman and Company: New York, 2008; pp 184-233.

(2) Sendler, M.; Maertin, S.; John, D.; Persike, M.; Weiss, F. U.; Krüger, B.; Wartmann, T.; Wagh, P.; Halangk, W.; Schaschke, N.; Mayerle, J.; Lerch, M. Cathepsin B activity initiates apoptosis via digestive protease activation in pancreatic acinar cells and experimental pancreatitis. J. Biol. Chem. 2016, 291, 14717-14731.

(3) Ruseler-van Embden, J. G. H.; van Lieshout, L. M. C.; Smits, S. A.; van Kessel, I.; Laman, J. D. Potato tuber proteins efficiently inhibit human faecal proteolytic activity: implications for treatment of perianal dermatitis. Eur. J. Clin. Invest. 2004, 34, 303-311.

(4) Ryan, C. A.; Balls, A. K. An inhibitor of chymotrypsin from Solanum tuberosum and its behaviour towards trypsin. Proc. Natl. Acad. Sci. U.S.A. 1962, 48, 1839-1844.

(5) Rancour, J. M.; Ryan, C. A. Isolation of a Carboxypeptidase B inhibitor from Potato. Arch. Biochem. Biophys. 1968, 125, 380-383.

(6) Ryan, C. A. Isolation of carboxypeptidase A by a naturally occurring polypeptide from potato. Biochem. Biophys. Res. Commun. 1971, 44, 1265-1270.

(7) Kennedy, A. R. The Bowman-Birk inhibitor from soybeans as an anticarcinogenic agent. Am. J. Clin. Nutr. 1998, 68, 1406S-1412S.

(8) Huang, C.; Ma, W.-Y.; Ryan, C. A.; Dong, Z. 1997. Proteinase inhibitors I and II from potatoes specifically block UV-induced activator protein-1 activation through a pathway that is independent of extracellular signal-regulated kinases, c-jun Nterminal kinases, and P38 kinase. Proc. Natl. Acad. Sci. U.S.A. 1997, 94, 11957-11962.

(9) Kennedy, A. R. Chemopreventive agents: Protease inhibitors. Pharmacol. Ther. 1998, 78, 167-209.

(10) Valueva, T. A.; Revina, T. A.; Mosolov, V. V.; Mentele, R. Primary Structure of Potato Kunitz-Type Serine Proteinase Inhibito. Biol. Chem. 2000, 381, 2000-2012.

(11) Pouvreau, L.; Gruppen, H.; van koningsveld, G. A.; van den Broek, L. A. M.; Voragen, A. G. J. The most abundant protease inhibitor in potato tuber (cv. Elkana) is a serine protease inhibitor from the Kunitz Family. J. Agric. Food Chem. 2003, 51, 5001-5005.

(12) Pouvreau, L.; Gruppen, H.; Piersma, S. R.; van den Broek, L. A. M.; van Koningsveld, G. A.; Voragen, A. G. J. Relative abundance and inhibitory distribution of protease inhibitors in potato juice from cv. Elkana. J. Agric. Food Chem. 2001, 49, 2864-2874.

(13) Meulenbroek, E. M.; Thomassen, E. A. J.; Pouvreau, L.; Abrahams, J. P.; Gruppen, H.; Pannu, N. S. Structure of a posttranslationally processed heterodimeric double-headed Kunitz-type serine protease inhibitor from potato. Acta Crystallogr., Sect. D: Biol. Crystallogr. 2012, 794-799.

(14) Billinger, E.; Zuo, S.; Lundmark, K.; Johansson, G. Light scattering determination of the stoichiometry for protease-potato serine protease inhibitor complexes. Anal. Biochem. 2019, 582, No. 113357.

(15) Berger, S.; Rufener, J.; Klimek, P.; Zachariou, Z.; Boillat, C. Effects of potato-derived protease inhibitors on perianal dermatitis after colon resection for long-segment Hirschsprung's disease. World J. Pediatr. 2012, 8, 173-176.

(16) Marshall, J. J. Am. Chem. Soc. Symp. Ser. 1980, 12, 125.

(17) Pasut, G. Polymer for protein conjugation. Polymers 2014, 6, $160-178$.

(18) Varshosaz, J. Dextran conjugates in drug delivery. Expert Opin. Drug Delivery 2012, 9, 509-523.

(19) BeMiller, J. N. Dextran. In Encyclopedia of Food Sciences and Nutrition, 2nd ed.; Academic Press: 2003; pp 1772-1773.

(20) Takakura, Y.; Kaneko, Y.; Fujita, T.; Hashida, M.; Maeda, H.; Sezaki, H. Control of pharmaceutical properties of soybean trypsin inhibitor by conjugation with dextran I: Synthesis and characterization. J. Pharm. Sci. 1989, 78, 117-121.

(21) Kato, A.; Kameyama, K.; Takagi, T. Molecular weight determination and compositional analysis of dextran-protein conjugates using low-angle laser light scattering technique combined with high-performance gel chromatography. Biochim. Biophys. Acta, Protein Struct. Mol. Enzymol. 1992, 1159, 22-28. 
(22) Bethell, G. S.; Ayers, J. S.; Hancock, W. S. A novel method of activation of cross-linked agaroses with 1,1'-Carbonyldiimidazole which gives a matrix for affinity chromatography devoid of additional charged groups. J. Biol. Chem. 1979, 254, 2572-2574.

(23) Beeckmans, S. Chromatographic methods to study proteinprotein interactions. Methods 1999, 19, 278-305.

(24) Kojima, T.; Hashida, M.; Muranishi, S.; Sezaki, H. Mitomycin C-dextran conjugate: a novel high molecular weight pro-drug of mitomycin C. J. Pharm. Pharmacol. 1980, 32, 30-34.

(25) Takakura, Y.; Takagi, A.; Hashida, M.; Sezaki, H. Disposition and tumor localization of mitomycin C-dextran conjugates in mice. Pharm. Res. 1987, 4, 293-300.

(26) Axén, R.; Ernback, S. Chemical fixation of enzymes to cyanogen halide activated polysaccharide carriers. Eur. J. Biochem. 1971, 18, 351-360.

(27) Larionova, N. I.; Kazanskaya, N. F.; Yu Sakharov, I. Soluble high-molecular-weight derivatives of the pancreatic trypsin inhibitor, production and properties of the pancreatic inhibitor bound to dextran. Biochemistry 1977, 42, 963-968.

(28) Larionova, N. I.; Kazanskaya, N. F.; Yu Sakharov, I. Soluble high-molecular-weight derivatives of the pancreatic trypsin inhibitor, production and properties of the pancreatic inhibitor associated with carboxymethylcellulose and diethylamino ethyldextran. Biochemistry 1978, 43, 699-703.

(29) Sundberg, L.; Porath, J. Preparation of adsorbents for biospecific affinity chromatography. J. Chromatogr. 1974, 90, 87-98.

(30) Porath, J.; Axén, R. Immobilization of enzymes to agar, agarose and sephadex supports. Methods Enzymol. 1976, 44, 19-45.

(31) Eldjarn, L.; Jellum, E.; et al. Organomercurial-polysaccharide, a chromatographic material for the separation and isolation of SHproteins. Acta Chem. Scand. 1963, 17, 2610-2621.

(32) Valueva, T. A.; Revina, T. A.; Mosolov, V. V. Reactive sites of the $21-\mathrm{kDa}$ protein inhibitor of serine proteinases from potato tubers. Biochemistry 1999, 64, 1074-1078.

(33) Valueva, T. A.; Parfenov, I. A.; Revina, T. A.; Morozkina, E. V.; Benevolensky, S. V. Structure and properties of the potato chymotrypsin inhibitor. Plant Physiol. Biochem. 2012, 52, 83-90.

(34) Miller, G. L. Use of dinitrosalicylic acid reagent for determination of reducing sugar. Anal. Chem. 1959, 31, 426-428.

(35) Billinger, E.; Johansson, G. Kinetic studies of serine protease inhibitors in simple and rapid 'active barrier' model system - Diffusion through an inhibitor barrier. Anal. Biochem. 2018, 546, 43-49. 